\title{
Efecto antimicrobiano de la vitamina c, vitamina e y aceite esencial de romero (rosmarinus oficinalis) en salchichas de pollo tipo frankfurt
}

RECIBIDO: 11/01/2017 ACEPTADO: 18/05/2017

Janeth Proaño Bastidas ${ }^{1}$ Paula UrResta Valencia ${ }^{2}$ MaURicio Racines OLIVA ${ }^{3}$

\begin{abstract}
RESUMEN
Se determinó el efecto antimicrobiano de la vitamina C, la vitamina E y el aceite esencial de romero (Rosmaninus oficinalis). Se prepararon doce soluciones en diferentes concentraciones y un testigo con butil hidroxi tolueno (BHT), se aplicó a las salchichas de pollo tipo frankfurt, que fueron empacadas al vacío y almacenadas a $40 \mathrm{C}$, durante 30 días. El efecto antimicrobiano se determinó utilizando agares específicos para E. coli, S. aureus, Salmonella sp y aerobios mesófilos, se midió la cantidad de unidades formadoras de colonias (ufc), cada cinco días hasta los 30 días. Se logró inhibir por completo la presencia de Salmonella $s p$ y E. coli. Para aerobios mesófilos y S. aureus la cantidad de ufc se mantuvo en límites inferiores a los aceptados por la norma INEN 13882010 del Ecuador. Se concluye que los tratamientos aplicados pueden sustituir a los preservantes químicos, manteniendo una vida útil de las salchichas por 30 días.
\end{abstract}

Palabras claves. E. coli; S. aureus; Salmonella sp; aerobios mesófilos.

ANTIMICROBIAL EFFECT OF VITAMIN C, VITAMIN E AND ESSENTIAL OIL OF ROMERO (ROSMARINUS OFICINALIS) IN FRANKFURT CHICKEN SAUSAGES

\section{ABSTRAT}

The antimicrobial effect of vitamin C, vitamin E and rosemary essential oil (Rosmaninus oficinalis) was determined. Twelve solutions at different concentrations, coupled with a control with butyl hydroxy toluene were prepared and applied to the chicken sausage frankfurters, which were subsequently vacuum packed and stored at $4 \mathrm{C}$ for 30 days. The antimicrobial effect was determined by the use of specific agars for $E$ coli, s. aureus, salmonella $s p$, mesophilic aerobes. The number of colony forming units (cfu) was quantified every five days for a period of 30 days. This method revealed that it was possible to completely inhibit the presence of Salmonella $s p$ and E. coli. Moreover, aerobic mesophilic and $S$. aureus the amount of ufc aureus remained below accepted by the INEN Ecuador 13882010 standard limits. It is concluded that the applied treatments can replace chemical preservatives, maintaining the lifespan of the sausages for up to 30 days.

Keywords: E. coli; S. aureus; Salmonella sp; aerobic mesophilic.

\section{INTRODUCCIÓN}

En la actualidad existe una tendencia hacia una alimentación más saludable, basada en productos más frescos y sanos. Se ha asociado el consumo de preservantes alimenticios con intoxicaciones, cáncer y otras enfermedades degenerativas (Álvarez-Parrilla, 2006).

En las últimas décadas se produjeron muchos avances en la conservación de alimentos a través de agentes químicos, como son los benzoatos, sulfatos, propionatos, sorbatos, nitritos y nitratos, sin medir las consecuencias reales que éstos puedan causar a la salud (López, 2007). Se consumen millones de kilogramos de conservadores por año, solo en Estados Unidos en 1991 se consumieron 37.5 millones de kilogramos, y se estima que este consumo aumenta en un $4.1 \%$ anualmente (Davidson, 1997).

Los preservantes son añadidos a los alimentos en forma intencional para retardar el crecimiento microbiano, inactivar a los microrganismos, detener el deterioro de la calidad del producto, manteniendo la seguridad del alimento (Davidson,1997). Sin el uso de preservantes, se pierde el $20 \%$ de todos los alimentos producidos en el mundo y esto implica pérdidas económicas significativas tanto para fabricantes como para distribuidores y consumidores (Matamoros, 1998).

La industria alimentaria busca alternativas de conservación de los alimentos, utilizando anti-oxidantes naturales provenientes de plantas, para ofrecer al mercado productos sanos, seguros y de buena calidad (Inouye, Takizawa y Yamaguchi, 2001). Los antioxidantes naturales incluyen compuestos fenólicos, aceites esenciales provenientes de cortezas, tallos, hojas, flores, ácidos orgánicos (ácido $L$ ascórbico) presentes en frutos y fitoalexinas producidas en plantas (Beuchat, 2001).

Los aceites esenciales, son líquidos olorosos y aceitosos provenientes de diferentes partes de una planta. Son mezclas complejas de ésteres, aldehídos, cetonas y terpenos. Tienen propiedades antimicrobianas contra un amplio rango de bacterias y hongos (Bullerman, Ryu, Jackson y Bullerman,

\footnotetext{
Ingeniería Agroindustrial y de Alimentos.

Universidad de las Américas. Ecuador.j.proano@udlanet.ec. Profesor de tiempo completo.

Ingeniería Agroindustrial y de Alimentos.

Universidad de las Américas. Ecuador. murresta@udlanet.ec Estudiante

Ingeniería Agroindustrial y de Alimentos

Universidad de las Américas. Ecuador.m.racines@udlanet.ec. Profesor de tiempo completo.
} 
2001). Son muy efectivos contra bacterias gram positivas como los Bacillus, E coli, Salmolella (Soriano, 2007). Sensibilizan la membrana celular de los microrganismos hasta que la célula sufre daños graves y colapsa (Raibaudi, Fortuna y Belloso, 2006)

El aceite esencial de romero tiene poder antibacteriano (Oluwatuy, Kaatz y Gibbons, 2004) y es agente contra el cáncer (Leal, Braga, Sato, Carvalho, Marques, y Meireles, 2003). En el estudio realizado por Sebrabnek, Sewalt, Robbins y Houser (2005) se demostró que el aceite esencial de romero en una concentración de 500 a 3000 ppm tiene un efecto antioxidante en salchichas de cerdo mayor que el BHT que es un preservante químico, a 4 grados centígrados. La actividad antioxidante del aceite esencial de romero se debe a sus componentes principales ácido rosmarínico, ácido carmósico y carmasol (Frankel, Huang, Aeschbach y Prior, 1996).

Entre los ácidos orgánicos se tiene el ácido L-ascórbico (Vitamina C) que es uno de los compuestos naturales con mayor actividad antioxidante, gracias a que puede eliminar los radicales libres y reducir el estrés oxidativo en las células (Temple 2000). El ácido L-ascórbico en alimentos procesados ha dado buenos resultados como preservante alimentario (Kähkönen, Hopia, Vuorela, Rauha, Pihlaja, Kujala y Heinonen 1999). Cumple con funciones como secuestro de varias formas de oxígeno, reducción de radicales libres, frenando las reacciones en cadena y previniendo el daño a los alimentos (Núñez, 2011).

Además, se han considerado algunas vitaminas como preservantes naturales, como es el caso de la vitamina $\mathrm{E}$, que se la ha usado como presenvante de alimentos desde hace 50 años, especialmente en la conservación de alimentos grasos como mantecas, galletas, patatas fritas, etc (MaestroDurán, y Padilla, 1993). La ventaja de la vitamina $E$ es que al ser calentado el alimento graso, los tocoferoles permanecen estables y su efecto es mayor a otros antioxidantes naturales o químicos (Pongratz, 1988).

Se consideró estos tres antioxidantes naturales, aceite esencial de romero, ácido $L$ ascórbico y vitamina $\mathrm{E}$ para formular soluciones antioxidantes que fueron aplicadas en salchichas de pollo tipo Frankfurt para ofrecer al consumidor alimentos sin preservantes químicos y con una vida útil similar a la que ofrecen éstos.

\section{METODOLOGÍA}

Se prepararon doce soluciones antioxidantes a base de vitamina $C$, vitamina $E$ y aceite esencial de romero y una con el preservante químico $\mathrm{BHT}$, como se detalla en la Tabla 1.

Tabla 1. Combinaciones de Antioxidantes

\begin{tabular}{|l|r|r|r|r|}
\hline Tratamiento & AA ppm & VE ppm & AER ppm & $\begin{array}{c}\text { BHT } \\
\text { ppm }\end{array}$ \\
\hline T1 & 0 & 0 & 0 & 100 \\
\hline T2 & 5000 & 0 & 0 & 0 \\
\hline T3 & 0 & 5000 & 0 & 0 \\
\hline T4 & 0 & 0 & 500 & 0 \\
\hline T5 & 500 & 500 & 0 & 0 \\
\hline T6 & 0 & 500 & 200 & 0 \\
\hline T7 & 1000 & 1000 & 0 & 0 \\
\hline T8 & 1000 & 0 & 400 & 0 \\
\hline T9 & 0 & 1000 & 400 & 0 \\
\hline T10 & 1000 & 800 & 400 & 0 \\
\hline T11 & 800 & 800 & 300 & 0 \\
\hline T12 & 1000 & 1000 & 400 & 0 \\
\hline T13 & & & \\
\hline $\begin{array}{l}\text { AA= Ácido Ascórbico } \\
\text { VE= Vitamina E } \\
\text { AER= Aceite Esencial de Romero } \\
\text { BHT= butil hidroxi tolueno } \\
\text { ppm= partes por millón }\end{array}$ & & & & \\
\hline
\end{tabular}

Fuente: Elaboración propia

Estas soluciones se las preparó, considerando el peso de las soluciones antioxidantes con respecto al peso de la salchicha. La vitamina $\mathrm{C}$ y el aceite esencial de romero se los disolvió en agua mili $Q$ y la vitamina $\mathrm{E}$ en aceite de maíz.

\subsection{Elaboración de salchichas de pollo tipo Frankfurt}

Se prepararon las salchichas de pollo en los laboratorios de procesamiento de la Universidad de las Américas Quito (UDLA), previa una desinfección de mesones, equipos y utensilios con el ácido per acético en diferentes concentraciones.

Se fabricaron 1092 salchichas, a las cuales se les agregó las soluciones antioxidantes de los doce tratamientos más la solución de BHT, fueron empacadas al vacío en forma individual y se almacenó en refrigeración a temperatura de 4 oC durante 30 días. 


\subsection{Análisis Microbiológicos}

Se realizó un análisis microbiológico de las salchichas, para determinar la presencia de aeróbios mesófilos, Staplhylococcus aureus, Escherichia coli y Salmonela sp según los requerimientos de la Norma INEN 1338: 2010 (Tabla 2). Se realizaron los análisis el día de fabricación de las salchichas y cada 5 días hasta los 30 días luego de su elaboración.

Tabla 2. Requisitos microbiológicos para productos cárnicos cocidos

\begin{tabular}{|c|c|c|c|c|}
\hline Requisitos & $\mathrm{n}$ & c & $\mathbf{m}$ & $M$ \\
\hline Aerobios mesófilos ufc/g & 5 & 1 & $5.0^{*} 10^{5}$ & $1.0^{*} 10^{7}$ \\
\hline Escherichia coli ufc/g & 5 & 0 & $<3$ & - \\
\hline Staphylococcus aureus ufc/g & 5 & 1 & $1.0^{*} 10^{3}$ & $1.0^{*} 10^{4}$ \\
\hline Salmonela ufc $/ 25 g$ & 10 & 0 & ausencia & - \\
\hline \multicolumn{5}{|c|}{$\begin{array}{l}\mathrm{n}=\text { número de unidades de la muestra, } \mathrm{c}=\text { número de unidades } \\
\text { defectuosas, } \mathrm{m}=\text { nivel de aceptación, } \mathrm{M}=\text { nivel de rechazo, ufc= } \\
\text { unidades formadoras de colonias. }\end{array}$} \\
\hline
\end{tabular}

Fuentes: (Norma INEN, 2010)

\subsection{Procedimiento para siembra de muestras}

El procedimiento para la siembra de las muestras se realizó en la Cámara de Flujo Laminar Thermo Scientific 1300, para evitar contaminación cruzada. Se tomó un g. de la muestra de la salchicha de pollo, se colocó en un tubo de ensayo con tapa, que contenía $9 \mathrm{ml}$ de agua peptona, se agitó durante 10 minutos en el agitador BOECO PSU - 10i. Se colocó $100 \mu \mathrm{l}$ de la dilución en una caja Petri con el agar específico para cada bacteria, mediante el uso de una micropipeta Ecopipette Capp de 10$100 \mu \mathrm{l}$, se incubó a 37.5 grados centígrados, en la incubadora incucell durante 48 horas y se procedió a la lectura en el contador de colonias BOECO Germany CC-1, se expresó el resultado en ufc/g del alimento que fue calculado con la fórmula 1 , finalmente para culminar el proceso se coloca en el autoclave Tuttnauer 3870 para eliminar las muestras contaminas.

Fórmula 1 Ufc $=$ no.de colonias* $\mathrm{V}-1 \mathrm{ml}$ * (factor de dilución)-1

\section{Aerobios mesófilos}

Para la determinación de aerobios mesófilos se utilizó el agar nutritivo PCA (Plate Count Agar). Las unidades formadoras de colonias de aerobios en este agar aparecen de color amarillo blanquecino, de forma circular y de diversos tamaños, éstas se desarrollan en aerobiosis.

\section{Escherichia coli}

Para determinar Escherichia Coli se utilizó agar nutritivo EMB (Eosina-Azul de Metileno). Las unidades formadoras de $E$. coli se presentaron de color verde metálico con brillo y centro negro azulado de forma circular y diversos tamaños. Se incubó a $37.5^{\circ} \mathrm{C}$ durante un período de 48 horas.

\section{Staphylococcus aureus}

Se preparó agar nutritivo Manitol Salado en cajas Petri, se incubó a $37.5^{\circ} \mathrm{C}$ durante un período de 24 horas. Las unidades formadoras de $S$. aureus se presentaron de color amarillo, de forma circular y tamaño medio.

\section{Salmonella}

Se realizó un pre enriquecido, enriquecido y un aislamiento, con un caldo de Muller Kauffmann tetrationato y rappaport vassiliadis soja. Se realizó la siembra por agotamiento de estrías y se incubó a $42^{\circ} \mathrm{C}$ durante 24 horas, se contó las colonias de color rosa transparente y rojas intensas.

\subsection{Resultados y Discusión}

Se realizaron 13 tratamientos, al T1 se le adicionó un preservante químico $\mathrm{BHT}$, a este se lo consideró como testigo. Desde el T2 hasta el T13 se adicionó mezclas de vitamina $E$, vitamina $C$ y aceite esencial de romero en diferentes proporciones (Tabla 1). Se tomó datos del número de colonias de microrganismos que se formaron cada 5 días hasta los 30 días; con tres repeticiones.

En el procesamiento de los resultados se aplicó estadística básica, un análisis de varianza ANOVA, de bloques completos al azar. Se procesaron los datos mediante el programa estadístico Infostat y se determinó las soluciones antioxidantes óptimas para salchichas de pollo, mediante el método de superficies de respuesta en el programa Minitab.

\section{S. aureus}

Según la Norma INEN 1338: 2010 (Tabla 2) para productos cárnicos cocidos la cantidad máxima de ufc para $S$. aureus no debe sobrepasar de 1*10$3 \mathrm{ufc} / \mathrm{g}$ del alimento, los resultados obtenidos demuestran que los tratamientos $3,7,8,9,10,11$, 12,13 , no sobrepasan estos límites. El tratamiento 1 con BHT sobrepasó estos límites.

La Figura 1 representa el incremento de unidades formadoras de colonias a través de los 30 días de estudio, se graficaron los cuatro tratamientos con 
menor número de ufc, éstos son: 7, 8, 11, 12

\section{S. aureus}

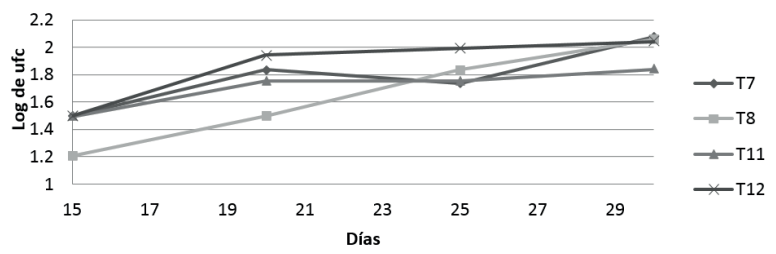

Figura 1: Curva de crecimiento de S. aureus en salchichas de pollo tipo Frankfurt

Fuente: Elaboración propia.

El día 30 reportó la mayor cantidad de ufc (Figura 2) el tratamiento 12 es el que inhibió de mejor manera la proliferación de colonias de $S$. aureus, con un valor de 155 ufc.

Se realizó el ANOVA de bloques totalmente al azar, se comparó los tratamientos por medio de la prueba de significancia de Tukey con $\alpha=0.05, N=364$ por cada repetición, se realizó tres repeticiones, esto reflejó que existen diferencias significativas entre los tratamientos a partir del día 10. En los días 0 y 5 no proliferan colonias de $S$. aureus, en los días 10,15 y 20 se observan muy pocas ufc, en los días

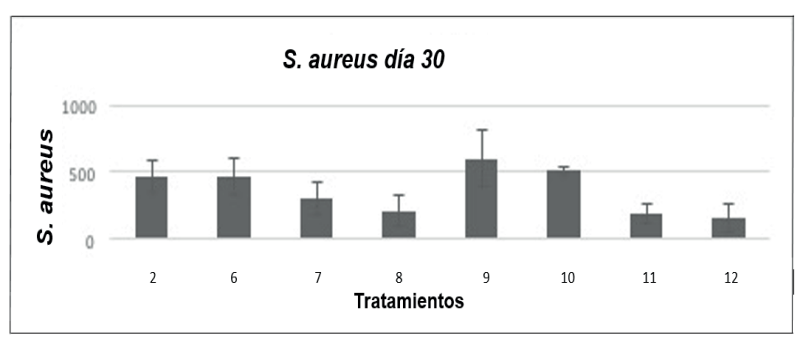

Figura 2: Unidades formadoras de colonias de S. aureus en el día 30.

Fuente: Elaboración propia.

25 y 30 se producen mayor cantidad de colonias. Los tratamientos similares con menores promedios de ufc de $\mathrm{S}$. aureus según Tukey son $7,8,11,12$, en el día 30 (Tabla 3). El T1 (100 ppm BHT) tiene promedios más altos de ufc que éstos tratamientos.

Con los 4 tratamientos que son significativamente semejantes según Tukey y que no sobrepasaron los límites de la norma INEN, se realizó una optimización para encontrar la mejor combinación de antioxidantes naturales, se utilizó el método de superficies de respuesta, en el programa Minitab, el modelo multivariante encontrado fue:

S. aureus $=17.34-0.04 \mathrm{AA}+0.12 \mathrm{AER}-0.03 \mathrm{VE}+5.9 * 10$ $5 \mathrm{AA}{ }^{*} \mathrm{AA}-3.42 * 10-4 \mathrm{AER}{ }^{*} \mathrm{AER}-1.52$ * $10-5 \mathrm{VE} * \mathrm{VE}$.

Tabla 3: Comparaciones de tratamientos por medio de la prueba de significancia de Tukey

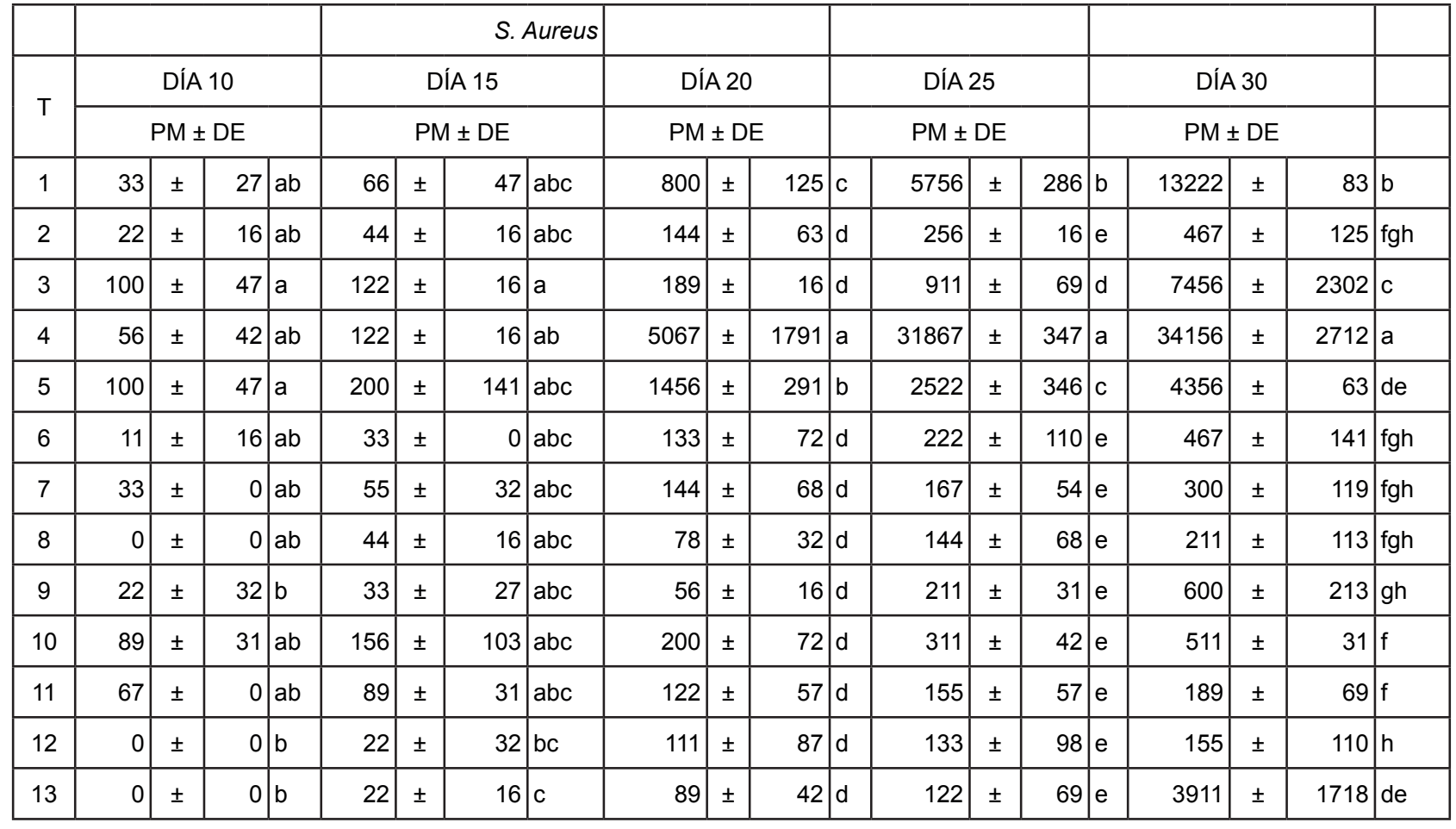

Fuente: Elaboración propia.

$\mathrm{PM}=$ Promedio

$\mathrm{DE}=$ desviación estándar 
En este caso las interacciones no son significativas por lo que se podría dejar el modelo como:

\section{S. aureus $=17.34-0.04 \mathrm{AA}+0.12 \mathrm{AER}-0.03 \mathrm{VE}$}

Se realizó una minimización por el método de superficie de respuesta, para obtener las combinaciones que produzcan menores promedios de ufc de $S$. aureus, las soluciones con valores cercanos a 400 ppm de ácido L ascórbico y 400 ppm de aceite esencial de romero produce el pico más bajo de colonias de $S$. aureus. Figura 4.

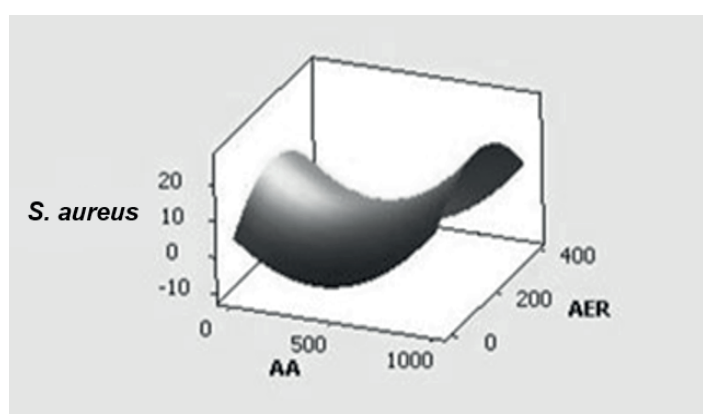

Figura 4. Unidades formadoras de colonias de $S$. Aureus en función de las concentraciones de AA vs AER

Fuente: Elaboración propia.

Las concentraciones con valores cercanos a 400 ppm de ácido $L$ ascórbico y valores próximos a $1000 \mathrm{ppm}$ de vitamina $\mathrm{E}$ producen menor número de ufc de $S$. aureus. Figura 5.

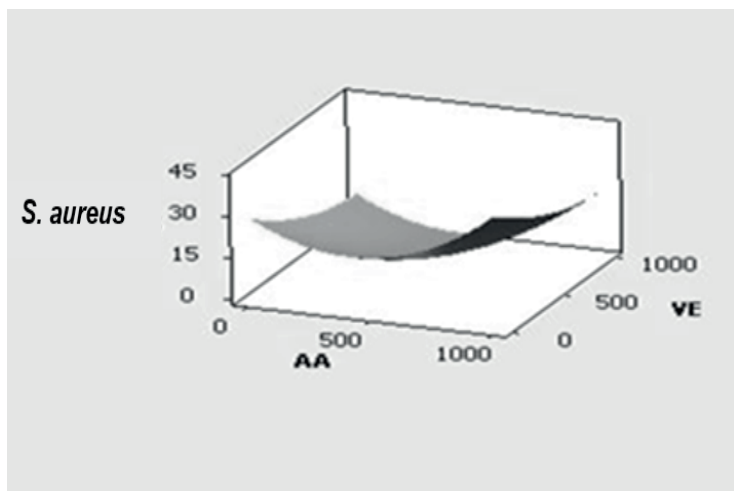

Figura 5: Unidades formadoras de colonias de S. Aureus en función de las concentraciones AA vs VE

Fuente: Elaboración propia.

Con concentraciones de $400 \mathrm{ppm}$ de aceite esencial de romero y 1000 ppm de vitamina $E$ se obtienen menores cantidades de ufc de $S$. aureus. Figura 6

Para obtener la combinación óptima de los tres antioxidantes naturales, por el método de superficies de respuesta, se realizó una minimización, el resultado obtenido fue: $404 \mathrm{ppm}$ de ácido L ascórbico, $400 \mathrm{ppm}$ de aceite esencial de romero y 1000 ppm de vitamina E.

Al comparar el tratamiento 12 (AA 800 ppm, AER 300ppm, VE 800 ppm) con la solución óptima, se concluyó que fue necesario la interacción de los tres antioxidantes para la inhibición óptima de cepas de $S$. aureus. Sin embargo, se puede utilizar concentraciones más bajas de ácido $L$ ascórbico lo que implica un ahorro de recursos. Y aumentar la cantidad de vitamina $E$ para que se controle mejor el deterioro de la grasa de la salchicha.

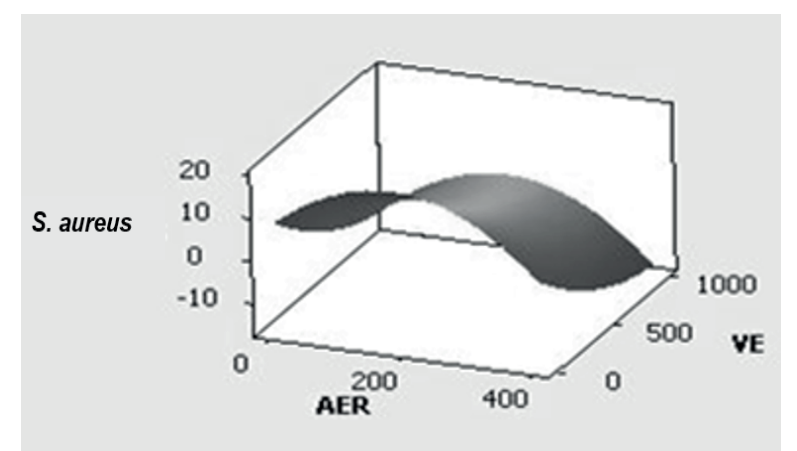

Figura 6. Unidades formadoras de colonias de S. Aureus en función de las concentraciones de AER vs VE

Fuente: Elaboración propia.

La concentración de la combinación optima implica 404 ppm de ácido $L$ ascórbico esto se confirma con los estudios de Martinez, Molina y Boucurt (1997) que demostraron la actividad antimicrobiana del ácido ascórbico en cepas de S.aureus, en productos cárnicos.

La cantidad de aceite esencial de romero en la combinación óptima es de 400 ppm esto tiene respaldo en las investigaciones de Moreira, Ponce, Del Valle y Roura, (2005) que realizaron estudios in vitro con aceite esencial de romero en alimentos, reportando que éste tiene un amplio espectro de acción antimicrobiana para bacterias gram positivas como S. aureus. El efecto combinado de los aceites esenciales puede ser igual a la suma de los efectos con respecto a los aceites probados individualmente, o es mayor que la suma de los efectos observados de los agentes probados. (Barry, 1976). En este caso se comprobó que los tratamientos 2, 3, 4 que contiene uno solo de éstos antioxidantes, AA (5000 ppm), VE (5000ppm), AER (500ppm) respectivamente, tienen un efecto antioxidante menor que el tratamiento 12 que tiene la mezcla de los tres. Además, se pudo observar que en la combinación óptima, la concentración de romero es $400 \mathrm{ppm}$, inferior a la concentración mínima inhibitoria del aceite esencial de romero para S. aureus que es de 1024 ppm (Klančnik, Guzej, Hadolin-Kolar, Abramovič y Smole-Možina, 2009) comprobándose que la combinación de antioxidantes naturales es mayor que los efectos 
individuales.

\section{Aerobios mesófilos}

La presencia de aerobios mesófilos en la muestra determinan la inocuidad del alimento, con respecto a la materia prima, manipulación, procesamiento y almacenaje (Andino \& Castillo, 2010).

En esta investigación con todos los tratamientos se controló la cantidad colonias de aerobios mesófilos durante los 30 días de investigación, la cantidad de ufc no sobrepasa el límite establecido por la norma INEN. A pesar de que la carne de pollo es un alimento que se contamina con mucha facilidad con aerobios mesófilos (Domínguez, Ávila, Carmona, Macías, Escalera y Mendoza, 2015)

La cantidad de colonias de aerobios mesófilos en las salchichas aumentan a medida que pasa el tiempo, en los días $0,5,10,15,20$ la cantidad de ufc son mínimas, todos los tratamientos dieron el mismo efecto, los días 25 y 30 reportaron mayor proliferación de bacterias. La figura 7 representa log ufc vs días de investigación de los 4 tratamientos que mejor inhibieron las colonias de aerobios mesófilos.

En los días 25 y 30 se produjo un aumento de colonias de aerobios mesófilos con un valor máximo de 32233 ufc para el tratamiento 5 , que contiene $500 \mathrm{ppm}$ de ácido ascórbico y $500 \mathrm{ppm}$ de vitamina $\mathrm{E}$, la figura 8 representa la cantidad de ufc en el día 30.

Los tratamientos que mejor inhibieron la proliferación de bacterias aeróbias, fueron el 2, 11, 13, al aplicar el T2 a las salchichas de pollo, se obtuvo 5093 ufc, el T11 fue 8300 ufc y el T13 fue 9833 ufc en el día 30. En estos tres tratamientos el contenido de ácido ascórbico es de 5000 ppm, 1000ppm y 1000 ppm respectivamente. Estos resultados se corroboran con Xong, Ho y Shahidi (2012) que afirmaron que el ácido ascórbico inhibe el crecimiento de bacterias aeróbicas en productos cárnicos.

Al realizar el ANOVA con pruebas de significación Tukey

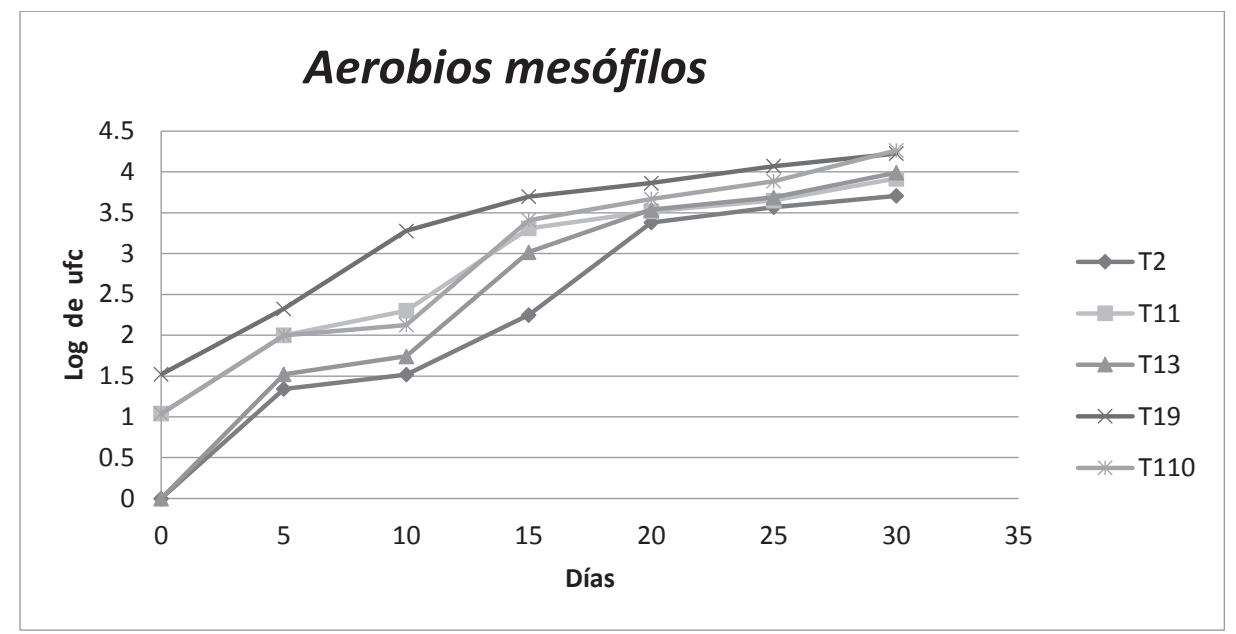

Figura 7: Curva de crecimiento de Aerobios mesófilos Fuente: Elaboración propia.

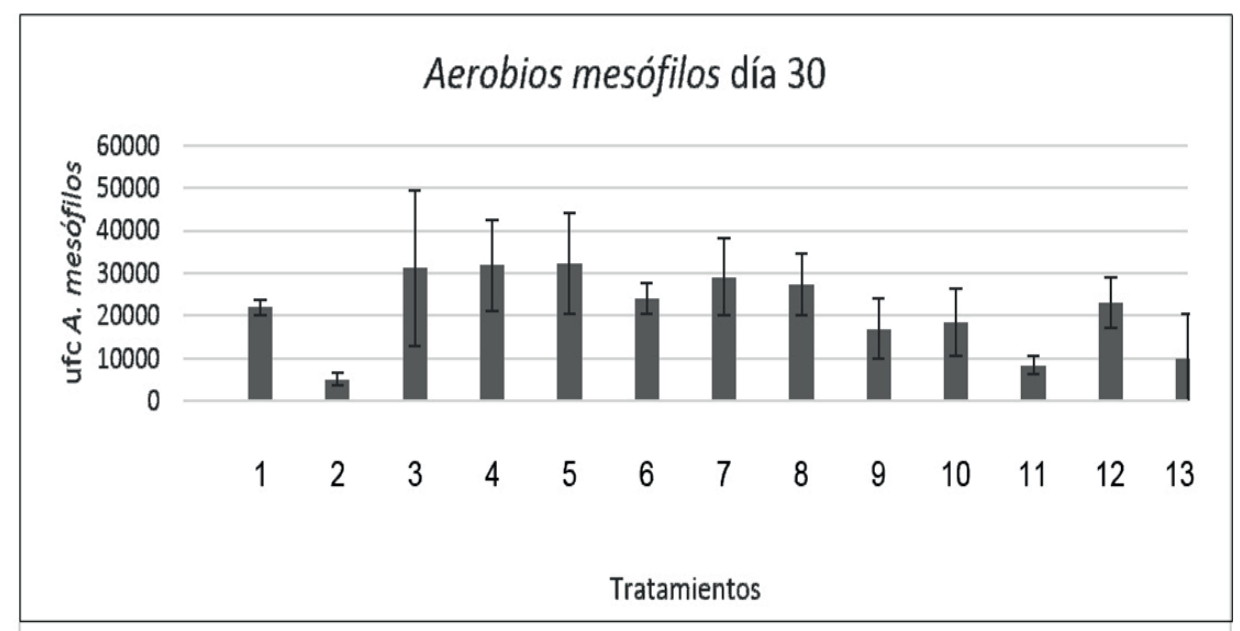

Figura 8: Unidades formadoras de colonias de Aerobios mesófilos en el dìa 30 Fuente: Elaboración propia. 
se puede observar que existen diferencias significativas entre los tratamientos aplicados para la inhibición de aerobios mesófilos, en los días 25 y 30 (Tabla 6). El T2 (5000 ppm AA) presentó mejor inhibición.

Tabla 6. Comparaciones de tratamientos con la prueba de significancia Tukey para aerobios mesófilos

\begin{tabular}{|c|r|l|l|r|l|l|}
\hline \multicolumn{7}{|c|}{ Areobios Mesófilos } \\
\hline \multirow{2}{*}{$\mathrm{T}$} & \multicolumn{3}{|c|}{ DÍA25 } & \multicolumn{3}{|c|}{ DÍA30 } \\
\cline { 2 - 7 } & \multicolumn{3}{|c|}{$\mathrm{PM} \pm \mathrm{DE}$} & \multicolumn{3}{|c|}{$\mathrm{PM} \pm \mathrm{DE}$} \\
\hline T1 & 13755 & \pm & $3105 \mathrm{ab}$ & 21967 & \pm & $1892 \mathrm{a}$ \\
\hline T2 & 3711 & \pm & $1107 \mathrm{ab}$ & 5093 & \pm & $1477 \mathrm{ab}$ \\
\hline T3 & 17067 & \pm & $20586 \mathrm{ab}$ & 31167 & \pm & $18192 \mathrm{ab}$ \\
\hline T4 & 23156 & \pm & $10024 \mathrm{ab}$ & 31839 & \pm & $10758 \mathrm{ab}$ \\
\hline T5 & 24078 & \pm & $8614 \mathrm{ab}$ & 32233 & \pm & $11848 \mathrm{ab}$ \\
\hline T6 & 17789 & \pm & $8554 \mathrm{ab}$ & 24022 & \pm & $3478 \mathrm{ab}$ \\
\hline T7 & 20622 & \pm & $10082 \mathrm{ab}$ & 29089 & \pm & $9052 \mathrm{ab}$ \\
\hline T8 & 21822 & \pm & $6782 \mathrm{ab}$ & 27245 & \pm & $7262 \mathrm{ab}$ \\
\hline T9 & 11789 & \pm & $4671 \mathrm{ab}$ & 16878 & \pm & $7089 \mathrm{ab}$ \\
\hline T10 & 7733 & \pm & $3535 \mathrm{ab}$ & 18367 & \pm & $7872 \mathrm{ab}$ \\
\hline T11 & 4478 & \pm & $2728 \mathrm{ab}$ & 8300 & \pm & $2127 \mathrm{ab}$ \\
\hline T12 & 12500 & \pm & $5967 \mathrm{ab}$ & 23045 & \pm & $5797 \mathrm{ab}$ \\
\hline T13 & 4878 & \pm & $4243 \mathrm{a}$ & 9833 & \pm & $10706 \mathrm{ab}$ \\
\hline
\end{tabular}

Fuente: Elaboración propia.

La prueba de Tukey establece 11 tratamientos con resultados similares (Tabla 6), para establecer cuál de éstos es mejor se realizó una prueba de optimización por el método de superficies de respuesta, se obtuvo el siguiente modelo multivariate,

Aerobios mesófilos $=205.8-0.03$ AA -0.13 AER + 4.52E-05 VE.

La optimización de la respuesta se obtuvo al realizar una minimización entre los rangos de 0 a 5000 ppm de ácido ascórbico (AA), aceite esencial de romero (AER) y vitamina $E$ (VE). La solución óptima fue 5000 ppm de AA, 500 ppm de AER y 0 ppm de VE.

Al realizar la minimización por el método de superficies de respuesta se obtuvo que mientras mayores son las concentraciones de ácido $L$ ascórbico hay mayor inhibición de bacterias de Aerobios mesófilos, llegando a concentraciones de 5000 ppm. La concentración de aceite esencial de romero está en valores cercanos a 500 ppm (Figura 9).

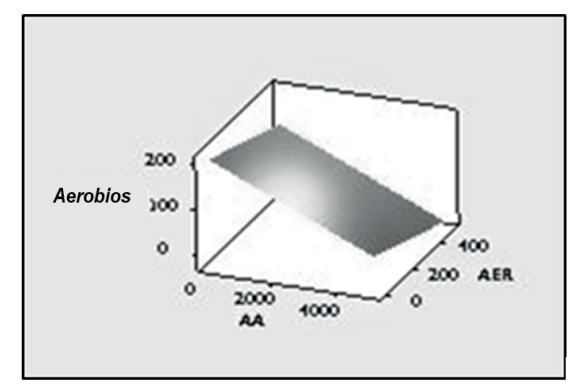

Figura 9: Unidades formadoras de colonias de Aerobios en función de las concentraciones de AA vs AER Fuente: Elaboración propia.
En la figura 10 se puede observar que la vitamina E no inhibe la cantidad de colonias de Aeróbios Mesófilos, es por esto que la combinación óptima no contiene vitamina $\mathrm{E}$.
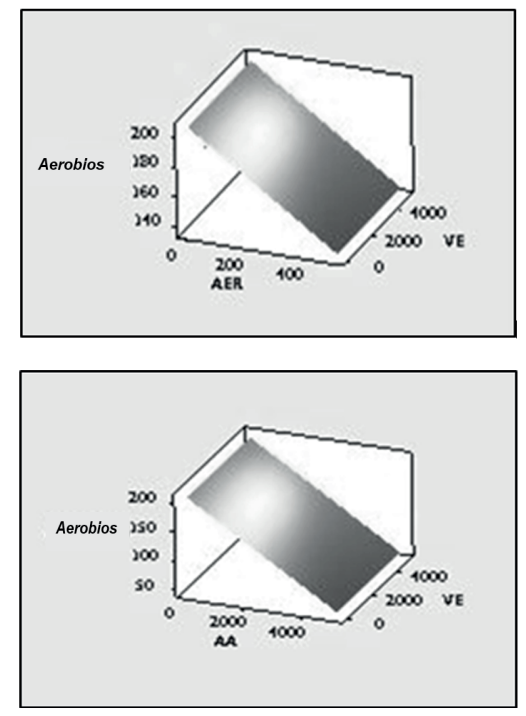

Figura10: Unidades formadoras de colonias de Aerobios en función de las concentraciones de AER vs VE y AA vs VE

Fuente: Elaboración propia.

Al comparar la concentración del tratamiento 2 (5000 ppm de AA) con la mezcla óptima (5000 ppm de AA y 500 ppm de AER), se observó que la concentración de AA es igual, sin embargo, no coincide la concentración AER, este tratamiento no dio los mejores resultados en cuento a inhibición de bacterias Aeróbicas, el tratamiento 9 contiene 1000 ppm de AA y 400 de AER es el que más se parece a la mezcla óptima, y controló mejor el crecimiento de bacterias Aeróbicas que el tratamiento 2, esto permite concluir que se produce un efecto sinergista entre el AA y AER, debido a que el MIC del AER para bacterias Aerobias esta entre 1000ppm a 2000 ppm, y este tratamiento tiene una concentración de AER menor que este rango (Raibaudi, Fortuna, Belloso, 2006). Este efecto está en relación con (Serrano, Guillén, Martínez-Romero, Castillo, Valero, 2005), que comprobó que el eugenol uno de los componentes del romero inhibe el crecimiento de bacterias aerobias mesófilas.

\section{E. Coli, Salmonella}

Todos los tratamientos inhiben totalmente la proliferación de bacterias E. coli y Salmonella, durante los 30 días de investigación no se desarrollaron colonias de estas dos bacterias. Estos resultados se sustentan en los estudios realizados por Martinez, Molina y Boucurt (1997) demostraron la actividad antimicrobiana del ácido ascórbico sobre productos cárnicos, en cepas de E. coli. 
Según Klancnik,et al., (2009) el aceite esencial de romero inhibe cepas de E. coli con un MIC de 4096 ppm, los tratamientos aplicados en esta investigación que contienen combinaciones de antioxidantes, no llegan a esta concentración de AER, por lo tanto se produce un resultado sumativo de los efectos causados individualmente por los antioxidantes naturales.

El estudio de Moreira et al, 2005 se identificó la actividad antimicrobiana del aceite esencial de hojas de romero contra varias cepas de E. coli. y Bozin y Mimica-Dukic (2007) encontraron que el aceite esencial de romero presenta una importante actividad antibacteriana contra cepas de E. coli. Esto confirma los resultados obtenidos en esta investigación.

El aceite esencial de romero inhibe las bacterias de Salmonella en una concentración de 512 ppm (Castaño, Ciro, Zapata, Jiménez, 2010) los tratamientos aplicados tienen valores menores a esta concentración, lo que permite concluir que existe un efecto sinergista entre los componentes de los tratamientos aplicados.

\section{CONCLUSIONES}

- El efecto antibacterial de la Vitamina C, Vitamina $\mathrm{E}$ y aceite esencial de romero (Rosmaninus oficianalis) en salchichas de pollo tipo Frankfurt presentó resultados positivos en las evaluaciones microbiológica. Las salchichas de pollo con soluciones antioxidantes naturales demostraron mejores resultados que la salchicha testigo con BHT.

- Todos los tratamientos inhiben la proliferación de bacterias E. coli, Salmonella, S. aureus y Aerobios mesófilos. Para E. coli y Salmonella se reportaron cero ufc durante los 30 días. Para $S$. aureus y aerobios mesófilos las ufc no sobrepasaron los límites dados por la norma INEN 1388 2010 del Ecuador, en los 30 días de investigación.

- Para S. aureus los tratamientos estadísticamente iguales según la prueba de significancia de Tukey son $7,8,11,12$, durante los 30 días, el tratamiento 12 (800ppm de AA, 800ppm de VE, $300 p p m$ AER) inhibió la proliferación de ufc de S. aureus reportando 155 ufc.

- Para S. aureus los tratamientos estadísticamente iguales según la prueba de significancia de Tukey son $7,8,11,12$, durante los 30 días, el tratamiento 12 (800ppm de AA, 800ppm de VE, $300 p p m$ AER) inhibió la proliferación de ufc de S. aureus reportando 155 ufc.
- El modelo multivariante para las combinaciones de antioxidantes obtenido por el método de superficies de respuesta es: $S$. aureus $=17.34$ 0.04 AA + 0.12 AER - 0.03 VE y la combinación de antioxidantes naturales óptima es 404 ppm de AA, 400 ppm de AER y 1000 ppm de VE.

- Para aerobios mesófilos los tratamientos con efectos iguales según la prueba de significancia de Tukey fueron todos con excepción del T1 (100 ppm BHT), durante los 30 días de investigación. De éstos los que tienen menores promedios de ufc son el T2 (5000 ppm de AA), T11 (1000ppm de AA, 800ppm de VE, 400 ppm de AER), T13 (1000ppm de AA, 1000ppm de VE, 400 ppm de AER). El tratamiento 6 (500ppm de AA, 500ppm de VE, 0 ppm de AER) inhibió las bacterias de aerobios mesófilos con un promedio mayor a todos los demás tratamientos con un resultado de 32233 ufc, sin embargo, éste valor sigue siendo menor que es el límite permitido por la norma INEN 13882010.

- Para aerobios mesófilos el modelo multivariante es: Aerobios mesófilos $=205.8-0.03$ AA -0.13 AER + 4.52E-05 VE y la combinación óptima obtenida es 5000 ppm de AA, 500 ppm de AER y 0 ppm de VE.

- Las combinaciones de antioxidantes de Vitamina C, Vitamina E y Aceite esencial de romero si sustituyeron a los preservantes químicos y conservaron las salchichas sin alteración microbiológicos durante 30 días.

\section{REFERENCIAS BIBLIOGRÁFÍCAS}

[1] Andino, F., \& Castillo, Y. (2010). Microbiología de alimentos. Universidad del Norte.

[2] Alvarez-Parrilla. (2006) Uso de agentes antimicrobianos para la conservación de frutas. Recuperado de http://www.ciad.mx/dtaov/XI 22CYTED/images/files_pdf/brasil/olga.pdf

[3] Maestro-Durán, R., y Padilla, R. (1993). Antioxidant activity of vitamin $\mathrm{C}, \mathrm{E}$, and provitamin A. Grasas y Aceites, 44(2), 107-111.

[4] Barry, T. N. (1976). The effectiveness of formaldehyde treatment in protecting dietary protein from rumen microbial degradation. Proceedings of the Nutrition Society, 221-229.

[5] Beuchat, L. (2001). Control of foodborne pathogens and spoilage microorganisms by naturally occurring antimicrobials. En: Microbial Food Contamination. Wilson CL, S Droby. (ED). CRC Press. London, UK. Chap. 11: 149169 
[6] Bozin, B. Y Mimica-Dukic, N., (2007). Los aceites esenciales de las especies de Lamiaceae antioxidantes como prometedor y agentes antimicrobianos. Naturales Comunicaciones del producto . 445-452

[7] Bullerman, L, Ryu, D., y Jackson, L (2002). La estabilidad de las fumonisinas en el procesamiento de alimentos. En micotoxinas y la seguridad alimentaria. Estados Unidos. 195-204

[8] Castaño, H. I., Ciro, G., Zapata, J. E., \& Jiménez, S. L. (2010). Actividad bactericida del extracto etanólico y del aceite esencial de hojas de Rosmarinus officinalis $\mathrm{L}$. sobre algunas bacterias de interés alimentario. Vitae, 17(2).

[9] Davidson, P. (1997). Chemical preservantes and natural antimicrobial compounds. Washington. D. C: ASM Press.

[10] Domínguez, P., Ávila, F., Carmona, C., Macías, H., Escalera, F., y Mendoza, J. (2015). Efecto del aceite de orégano adicionado en la dieta sobre la cantidad de mesófilos aerobios detectados en pechuga fresca y congelada de pollo. Abanico veterinario, 5(3), 13-19.

[11] Frankel, E. N., Huang, S. W., Aeschbach, R., \& Prior, E. (1996). Antioxidant activity of a rosemary extract and its constituents, carnosic acid, carnosol, and rosmarinic acid, in bulk oil and oil-in-water emulsion. Journal of Agricultural and Food Chemistry. 131-135

[12] INEN, N. T. E. 1338 (2012). Carne y productos cárnicos. Productos cárnicos crudos, productos cárnicos curados-madurados y productos cárnicos precocidos-cocidos. Requisitos. Recuperado de https://law. resource. org/pub/ec/ ibr/ec. nte, 1338.

[13] Inouye, S., Takizawa, T., \& Yamaguchi, H. (2001). Antibacterial activity of essential oils and their major constituents against respiratory tract pathogens by gaseous contact. Journal of antimicrobial chemotherapy, 47(5), 565573.

[14] Klančnik, A., Guzej, B., Hadolin-Kolar, M., Abramovič, H., y Smole-Možina, S. (2009). In vitro antimicrobial and antioxidant activity of commercial rosemary extract formulations. Journal of Food Protection. 1744-1752.

[15] Kähkönen, M. , Hopia, A., Vuorela, H., Rauha, J., Pihlaja, K., Kujala, T., \& Heinonen, M. (1999). Antioxidant activity of plant extracts containing phenolic compounds. Journal of agricultural and food chemistry. 3954-3962.
[16] Leal, P., Braga, M., Sato, D., Carvalho, J., Marques, M., y Meireles, M. (2003). Functional properties of spice extracts obtained via supercritical fluid extraction. Journal of Agricultural and Food Chemistry, 2520-2525.

[17] Lopez, F. (2007) Preelaboración y Conservación de Alimentos. Madrid. España. Amertown Internacional. S.A.

[18] Martínez, M., Molina, N., \&, Boucurt, E. (1997). Evaluación de la actividad antimicrobiana del Psidium guajava L.(guayaba). Revista Cubana de Plantas Medicinales, 2(1), 12-14.

[19] Matamoros, L. (1998). Aumenta el uso de antimicrobianos naturales en la UE para garantizar la seguridad de los alimentos manteniendo sus características. Recuperado de: http:// www. salud7. com. mx/nutricion/2006/12/antimicrobianosnaturales-y-conservacin. html.

[20] Moreira, M., Ponce, A., Del Valle, C. y Roura, S. (2005). Parámetros inhibitorios de aceites esenciales para reducir un patógeno de transmisión alimentaria. LWT-Food Ciencia y Tecnología . 565-570.

[21] Nuñez, G. (2011). Retos de la nueva industria alimentaria. Chile: Madero

[22] Oluwatuy, M., Kaatz, G., y Gibbons, S. (2004). Antibacteriana y resistencia a la actividad de la modificación de Rosmarinus officinalis. . Fitoquímica, 3249 - 3254.

[23] Pongracz. G. (1988). Heat stability of the tocopherols.- Fette Wiss. Technol 90. 247-251.

[24] Raibaudi, R., Fortuna, R., Belloso, O., 2006. Uso de agentes antimicrobianos para la conservación de frutas frescas y frescas cortadas. Universidad de Leida. Recuperado de: http:// www.ciad.mx/dtaov/XI_22CYTED/images/fi les_pdf/brasil/olga.pdf

[25] Sebranek, J., Sewalt, V., Robbins, K., y Houser, T. (2005). Comparación de un extracto de romero natural y BHA / BHT para la eficacia antioxidante relativa en la salchicha de cerdo. Meat Science. 289-296.

[26] Serrano, M., Guillén, F., Martínez-Romero, D., Castillo, S., y Valero, D. (2005). Los componentes químicos y la actividad antioxidante de la cereza dulce en diferentes etapas de maduración. Journal of Agricultural and Food Chemistry. 2741-2745.

[27] Soriano, J. (2007). Recursos genéticos, biodiversidad y derecho a la alimentación. Biodiversidad y Derecho a la Alimentación (Prosa- 
lus, coord.). Madrid, 39-65

[28] Takizawa, T. \& Yamaguchi, H. (2001). La actividad antibacteriana de los aceites esenciales y sus componentes principales contra patógenos de las vías respiratorias por contacto gaseoso. Diario de la quimioterapia antimicrobiana 565-573.
[29] Temple, N. (2000). Antioxidants and disease: more questions than answers. Nutrition research, 20(3), 449-459.

[30] Xiong, Y., Ho, C., \& Shahidi, F. (1999). Quality attributes of muscle foods. Springer Science \& Business Media. 